\title{
Team coaching in the workplace: Critical success factors for implementation
}

\begin{tabular}{|c|c|}
\hline \multicolumn{2}{|c|}{$\begin{array}{l}\text { Authors: } \\
\text { Badelisile M. Maseko }{ }^{1} \\
\text { Rene van } \mathrm{Wyk}^{1} \\
\text { Aletta Odendaal }\end{array}$} \\
\hline \multicolumn{2}{|c|}{$\begin{array}{l}\text { Affiliations: } \\
{ }^{1} \text { Department of Industrial } \\
\text { Psychology and People } \\
\text { Management, College of } \\
\text { Business and Economics, } \\
\text { University of Johannesburg, } \\
\text { Johannesburg, South Africa }\end{array}$} \\
\hline \multicolumn{2}{|c|}{$\begin{array}{l}{ }^{2} \text { Department of Industrial } \\
\text { Psychology, University of } \\
\text { Stellenbosch, Stellenbosch, } \\
\text { South Africa }\end{array}$} \\
\hline \multicolumn{2}{|c|}{$\begin{array}{l}\text { Corresponding author: } \\
\text { Rene van Wyk, } \\
\text { rvanwyk@uj.ac.za }\end{array}$} \\
\hline \multicolumn{2}{|c|}{$\begin{array}{l}\text { Received: } 04 \text { Oct. } 2018 \\
\text { Accepted: } 06 \text { Dec. } 2018 \\
\text { Published: } 30 \text { Apr. } 2019\end{array}$} \\
\hline \multicolumn{2}{|c|}{$\begin{array}{l}\text { How to cite this article: } \\
\text { Maseko, B.M., Van Wyk, R., } \\
\text { \& Odendaal, A. (2019). Team } \\
\text { coaching in the workplace: } \\
\text { Critical success factors for } \\
\text { implementation. SA Journal } \\
\text { of Human Resource } \\
\text { Management/SA Tydskrif } \\
\text { vir Menslikehulpbronbestuur, } \\
\text { 17(0), a1125. https://doi.org/ } \\
\text { 10.4102/sajhrm.v17i0.1125 }\end{array}$} \\
\hline \multicolumn{2}{|c|}{$\begin{array}{l}\text { Copyright: } \\
\text { (c) 2019. The Authors. } \\
\text { Licensee: AOSIS. This } \\
\text { is licensed under the } \\
\text { Creative Commons } \\
\text { Attribution License. }\end{array}$} \\
\hline \multicolumn{2}{|l|}{ Read online: } \\
\hline 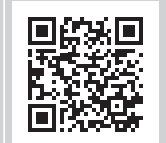 & $\begin{array}{l}\text { Scan this QR } \\
\text { code with your } \\
\text { smart phone or } \\
\text { mobile device } \\
\text { to read online. }\end{array}$ \\
\hline
\end{tabular}

Authors:

adelisile M. Maseko

Affiliations:

${ }^{1}$ Department of Industrial

Psychology and People

Management, College of

Business and Economics,

University of Johannesburg,

${ }^{2}$ Department of Industrial Psychology, University of

Stellenbosch, Stellenbosch,

\section{Rene van Wyk}

Dates:

Received: 04

Accepted: 06 Dec. 2018

blished: 30 Apr. 2019

\& Odendaal, A. (2019). Team

coaching in the workplace:

of Human Resource

Management/SA Tydskrif

17(0), a1125. https://doi.org/

Copyright:

Licensee: AOSIS. This work

is licensed under the

Creative Commons

mobile device

to read online.
Orientation: There is a scant availability of clear practice guidelines for the implementation of team coaching in organisations. Challenges and enabling factors in the implementation of team coaching require further exploration.

Research purpose: This study aims to develop a conceptual framework that identifies the critical success factors that play a role in the implementation of team coaching in organisations.

Motivation for the study: This study contributes towards the understanding of team coaching implementation in the workplace. Informed knowledge of critical factors may guide the practice of team coaching and assist in the development of a conceptual framework for such coaching.

Research approach/design and method: A constructivist qualitative research method was adopted. A case study approach was used, with seven experienced subject matter experts selected by means of purposive snowballing. Data were collected using semi-structured interviews and analysed using thematic analysis.

Main findings: Results of the thematic analysis indicate that to integrate successful team coaching into any organisation, effective analysis of an organisational context is required, that is, leadership stakeholders, team effectiveness, competency of a coach and employee engagement. Constraints that may prevent successful implementation of team coaching are identified.

Practical/managerial implications: The findings provide a platform to enhance the understanding and knowledge of the complexities of team coaching within organisations.

Contribution/value-add: The main contribution of the study is the identification of critical factors in the pre-, during and post-implementation phases of team coaching. This conceptual framework could serve as a guide for team coaching interventions in South African contexts.

Keywords: team coaching; team coaching enablers; team coaching constraints.

\section{Introduction}

Effective leadership is important for organisational survival and growth, especially in today's dynamic global business environment. Coaching is a planned intervention and part of a strategy for leadership development that is aligned with organisational strategic objectives (Reich, Ullmann, Van der Loos, \& Leifer, 2009). Traditionally, coaching has focused on individual empowerment and achievements. Organisations are now beginning to rely on team coaching to enhance organisational performance (Hackman \& Wageman, 2005). Even though organisations depend on teams to achieve their goals (Kozlowski \& Ilgen, 2006), many leaders are uncertain of how to optimally lead their teams in order to enhance performance (Wageman, Fisher, \& Hackman, 2009).

Research on coaching in practice appears to mainly focus on coaching individuals, managers and executives and less on team coaching (Klein, 2012). The lack of empirical evidence in the full value chain from need identification to implementation is regarded as a weakness in the research into team coaching (Hagen \& Aguilar, 2012; Peters \& Carr, 2013b). Reviewing South African literature, there appears to be a lack of research with regard to team coaching in organisations. However, in support of the effectiveness of team coaching, two South African studies suggest that collective coaching is more effective than dyadic coaching (Martiz, 2012; Reid, 2012). There is also a call for coaching interventions to evolve beyond one-on-one to collective coaching (Martiz, 2012). 


\section{Purpose}

The aim of this study was to identify critical factors that could enable organisations to implement team coaching.

\section{Coaching: An overview}

Traditionally, coaching has been anchored in western approaches that value individualism and achievement (Joo, 2005; Kampa-Kokesch \& Anderson, 2001). The focus has been on individuals, leadership development and the growth of the leader's capacity to take on effective leadership roles and responsibilities. Coaching is furthermore used as a tool to assist the coachee in realising sustainable change and personal development (McDermott, Levenson, \& Newton, 2007; Odendaal, 2016). Given the amount of attention devoted to the topic of coaching, one might expect that there would be a common agreement on its definition (Clutterbuck, 2013; Hamlin, Ellinger, \& Beattie, 2008). This is not, however, the case. Currently, the definitions of coaching reflect the diversity of contexts or domains in which the practitioner operates, the specific methodological approach employed and the outcomes to be achieved (Standards Australia, 2010). Descriptions of coaching that are in line with the purpose of this study define coaching as a process of helping individuals or teams in achieving their goals (Grant, 2012a; KampaKokesch \& Anderson, 2001).

\section{Team coaching}

Group coaching is at times used interchangeably with team coaching, but the current study will use group coaching and team coaching as differentiated terms. In group coaching, members come together as relative strangers, and the purpose is explicitly to facilitate the self-directed learning of the members, using a variety of individual goals in a crossfertilising learning experience (Hawkins, 2014). Team coaching, as a collective strategic intervention, focuses on the improvement of team productivity, increased engagement levels and reaching commonly agreed team goals (Bandura \& Lyons, 2017; Morgeson, DeRue, \& Karam, 2010). Team coaching augments performance, collaborations, synergies and the alignment of employees towards achieving a common goal (Clutterbuck, 2013; Hackman \& Wageman, 2005; Peters \& Carr, 2013a, 2013b; Thornton, 2010). It is a process whereby a coach works with the entire team, with one common objective aimed at assisting participants in attaining their full potential. Team members, however, share responsibilities and expertise, resulting in the team being increasingly recognised as more effective than individuals (Mathieu, Heffner, Goodwin, Salas, \& Cannon-Bowers, 2000).

The coaching of a team is seen as a powerful strategy in organisational development (Clarke, 2010). When a team is coached, knowledge is transferred from individuals to work for the team, with positive organisational outcomes (Rousseau, Aubé, \& Tremblay, 2013). Teams provide the platform for knowledge sharing and exchange, of which organisational learning becomes the product. Therefore, team learning is evident where there are transformed skills, knowledge and behaviour in the team (Sessa, London, Pingor, Gullu, \& Patel, 2011; Vesso \& Alas, 2016).

Numerous factors determine the efficacy of this form of intervention. Team characteristics play an important role in encouraging participation in all activities. The greater the social support and competence of the team, the better the participation levels within the team (Solansky \& McIver, 2017). Self-reflection and self-awareness practices are critical for a team to uncover their learning processes (Peuker \& Kiss, 2018). It is of fundamental importance that the team coaching process takes place in a favourable environment to yield positive results (Ingleton, 2013).

A case analysis of team coaching indicated that team coaching initiatives should be linked to organisational strategies and objectives (Mukherjee, 2012). All stakeholders' expectations must be recognised and aligned to the organisational goals, especially where the organisation is the ultimate sponsor of such an intervention. Sufficient resources and active leadership support are critical factors in ensuring that coaching is successfully implemented, as interventions are often not successful without executive backing (Avolio, Avey, \& Quisenberry, 2010; Goldman, Wesner, \& Karnchanomai, 2013). Indeed, the coaching of managers improves both team and individual learning (Matsuo, 2018).

Accurate assessment of the impact of interventions, such as coaching, is not easy to obtain other than through the solicitation of feedback from participants. However, welldesigned pre- and post-coaching evaluation questionnaires may be useful in ascertaining the effectiveness of a team coaching programme (Rousseau et al., 2013). Team diagnostics and assessments early in the implementation of a coaching programme are key to establish the needs of a client, which in turn must inform the design of a coaching programme (Britton, 2015; Rekalde, Landeta, \& Albizu, 2015). It would also be instructive to track the operational performance of the team over an extended period of time after team coaching (Anderson, 2011; Avolio et al., 2010; Osatuke, Yanovsky, \& Ramsel, 2016).

A team coaching contract must preferably be employed, setting out the roles and responsibilities of all stakeholders, rules of engagement and accountability of the coach to an identified party within the organisation (Kahn, 2011). Failure to do so may result in restricted accountability and unnecessary discomfort. At the outset of the intervention, the coach and the coachees must establish mutual understanding with regard to trust, confidentiality and empathetic response (Clutterbuck, 2013).

\section{Constraints to team coaching}

The absence of leadership support and lack of resources will adversely affect the team coaching intervention (Anderson, 2011; Chapman, 2010). This may also reduce the interest in the programme and thus affect participation (Ashley-Timms, 2012; Goldman et al., 2013). The presence of rigid silos and 
the absence of collaboration and commitment, which are endemic and characteristics of an organisational culture, may pose a potential threat to successful team coaching implementation (Bond \& Naughton, 2011). Lastly, inadequate coaching experience and a poor appreciation of team dynamics can undermine the team coach's good intentions and effectively derail the coaching project (Yates, 2015).

\section{Problem statement}

From the review of the literature, it is evident that the availability of clear practice guidelines regarding the implementation of team coaching in organisations is limited. Challenges and factors that facilitate the implementation of team coaching, especially within the South African context, require further exploration. Against this background, the aim of this study is to explore and describe critical success factors that may enable organisations to implement effective team coaching.

\section{Research question}

The main research question posed is the following: what are the critical success factors that need to be taken into consideration for the implementation of team coaching?

\section{Method}

A qualitative research method was adopted to explore and accumulate descriptive data regarding the implementation of team coaching as a phenomenon. Qualitative research affords the opportunity to gain detailed knowledge and a better understanding of opinions, experiences and thoughts as presented by respondents (Miles, Huberman, \& Saldana, 2013). Based on the ontological and epistemological assumption that the experiences of research participants will be subjective, the constructivist paradigm allows for the interpretation of the observed phenomena (Scotland, 2012). The ontological view of reality follows an epistemological subjective reality that interprets knowledge as socially constructed through the interconnected patterns of the integration of the different perspectives of participants.

\section{Research strategy}

This study applied a case study strategy to answer the research question. This research strategy was used to collect comprehensive data from experts in coaching (Leedy \& Ormord, 2001), with the purpose of understanding team coaching implementation. A case study inquiry allows the researcher to address the complexity of social phenomena (Baxter \& Jack, 2008; Blumberg, Cooper, \& Schindler, 2011), in this case coaching expertise. The principles of thematic analysis are applied to provide clarity on this phenomenon.

\section{Participants}

Two non-probability sampling procedures were utilised: purposive and snowballing techniques. The participants were deliberately chosen to reflect a unit of analysis and process of interest (Mayan, 2009; Welman, Kruger, \& Mitchell, 2005) of having expertise in the field of team coaching. Sampling parameters were centred on the participants being subject matter experts in the coaching field and having implemented team coaching. Selection criteria required that participants had at least 5 years of experience in executive coaching in any economic sector and had implemented team coaching interventions within organisations. The sample comprised four men and three women, with age ranging from 36 to 67 years. All the participants had more than 5 years of experience, ranging from individual to executive and team coaching. They had all implemented team coaching in various private- and public-sector industries, such as engineering, financial services, mining and manufacturing.

\section{Procedure}

The research focused on seven team coaching practitioners with specific expertise in team coaching in the workplace. Individual semi-structured interviews were conducted with the team coaching practitioners. Access to the participants was gained via email invitation to participate in the study, and the snowballing technique assisted in obtaining additional participants. The purpose of the research, as well as ethical considerations of anonymity and confidentiality, was explained. All interviews were recorded and field notes were taken with permission.

\section{Data collection method}

Two rounds of semi-structured interviews were conducted. Saturation was determined when no new information was generated from the participants (Greeff, 2005; Mayan, 2009). Permission to record the interviews was obtained from the participants prior to the interviews. For the purpose of eliciting in-depth responses, a semi-structured interview schedule was formulated to keep the interviewing process focused on the research objectives. This ensured consistency across different interviews. Interviews were fully transcribed to provide raw data for an orderly analysis. Audio recordings further allowed for the capture of information that could have been missed during note-taking (Guest \& Mitchell, 2007). A hand-written journal of personal notes was made after each interview and while listening to audio recordings. The journal enabled the recording and reflection of observations, during and immediately after each interview. The first phase of semi-interviews solicited individual, in-depth, detailed information from the respondents. The second phase of interviews facilitated clarification and confirmation from the initial respondents.

\section{Data analysis}

All the interviews and raw field notes were captured and transcribed (Pope, Ziebland, \& Mays, 2000; Welman et al., 2005). Audio recordings were transcribed verbatim, without changing their intended meaning (Patton, 1990; Pope et al., 2000). Thematic analysis was employed and emerging codes and themes were identified. First- and second-level interpretations were used for analysing the data and 
verifying patterns and themes (Collis \& Hussey, 2009; Newman, 2012). The process involved identification and coding of significant phrases in terms of insights they furnished into key enablers, constraints and challenges, as well as outputs of the process of implementing team coaching. Comparisons and contrasting ideas allowed for analysed variations in answers, resulting in common central themes and individual uniqueness (Welman et al., 2005).

\section{Ethical considerations}

The participants were informed about the objectives of the study and that participation was voluntary. It was made clear that participants could opt out without any negative consequences. The participants were assured that anonymity and confidentiality would be maintained by numbering the participants, with non-disclosure of organisations where team interventions had taken place. To incentivise their contribution to the study, participants have been granted access to the completed research report. Permission was obtained from the University of Johannesburg's ethics committee (Ethical clearance number: FOM2017IPPM068).

\section{Findings}

Seven main themes emerged from the analysis of the findings: (1) organisational culture, (2) coaching agreement, (3) team effectiveness, (4) common team goal, (5) engagement, (6) competencies of the coach and (7) constraining factors. These themes are summarised in Table 1 and explained in the discussion that follows.

TABLE 1: Main themes that support team coaching (current authors)

\begin{tabular}{|c|c|}
\hline Themes & Subthemes \\
\hline $\begin{array}{l}\text { 1. Organisational } \\
\text { culture }\end{array}$ & $\begin{array}{l}\text { Culture sets the tone } \\
\text { Safe receptive, trusting environment } \\
\text { Organisational readiness } \\
-\quad \text { to bring about change } \\
-\quad \text { shared vision } \\
\text { Leadership support }\end{array}$ \\
\hline $\begin{array}{l}\text { 2. Coaching } \\
\text { agreement }\end{array}$ & $\begin{array}{l}\text { Agreement between client and coach } \\
\text { Agreement in line with organisational vision } \\
\text { Agreement defines method, goals and expectations } \\
\text { Agreement clarifies agreed outcomes } \\
\text { Agreement allows for changes } \\
\text { Sufficient resources made available } \\
\text { Fulfilment of expectations of all stakeholders } \\
\text { Coach must manage conflicting ideas of stakeholders }\end{array}$ \\
\hline 3. Team effectiveness & $\begin{array}{l}\text { Cohesive collaboration of all team members } \\
\text { Coordination of organisational processes involved } \\
\text { Clarity of organisational strategy } \\
\text { Clarity regarding team deliverables }\end{array}$ \\
\hline 4. Common team goal & $\begin{array}{l}\text { Confidentiality } \\
\text { Alignment of all team members towards goals or objectives } \\
\text { Commitment to complete tasks } \\
\text { Consistent feedback in monitoring of process }\end{array}$ \\
\hline 5. Engagement & $\begin{array}{l}\text { Strategies must be clarified } \\
\text { Collaborative approach towards stakeholders } \\
\text { Continuous monitor and reflection } \\
\text { Regular progress evaluations } \\
\text { Post-intervention evaluations }\end{array}$ \\
\hline $\begin{array}{l}\text { 6. Competencies } \\
\text { of the coach }\end{array}$ & $\begin{array}{l}\text { Qualifications of the team coach } \\
\text { Skilled in dealing with team dynamics } \\
\text { Create safe space for individual expression }\end{array}$ \\
\hline $\begin{array}{l}\text { 7. Constraining } \\
\text { factors }\end{array}$ & $\begin{array}{l}\text { Lack of resources } \\
\text { Lack of time allocation } \\
\text { Inexperienced team coaches } \\
\text { Lack of transparency } \\
\text { Lack of integrity, trust and commitment to goals } \\
\text { Lack of leadership } \\
\text { Lack of trust between members } \\
\text { Absence of commitment } \\
\text { Interference due to personal agendas or clash of values } \\
\text { Silo effect }\end{array}$ \\
\hline
\end{tabular}

\section{Organisational culture}

Culture is regarded as the setting of tone of employee actions and leadership orientations, thus cultivating a platform for transparency and collaboration. A favourable organisational culture needs to be in place to produce a receptive environment for team coaching. This has to be done with 'open-mindedness, a flow of communication, cultural optimisation and acceptance, ... there must be trust' (Participant 3, male, 55 years old). The environment should be such that the team feels safe and trusts the system. Trust has to be ingrained within an environment that promotes open and honest communication.

There needs to be an organisational readiness (Participants 2 [female, 51 years old]; Participant 3 [male, 55 years old]; Participant 4 [female, 40 years old] and Participant 7 [male, 65 years old]) and willingness for organisational members to work together to bring about organisational change: 'the organisation must be ready for the intervention' (Participant 3 , male, 55 years old); 'One has to look at the rationale behind the organisation wanting to implement team coaching' (Participant 7, male, 65 years old). There needs to be a shared vision (Participants 3, [male, 55 years old]; Participant 4 [female, 40 years old] and Participant 7 [male, 65 years old]) that if various stakeholders are committed to implementing the change, one can be confident that their collective wisdom will bring about the desired results.

The majority of the participants indicated organisational culture supported by leadership as a key enabling factor for the successful implementation of team coaching. Leadership support is fundamental as a strategic priority in achieving the objectives of team coaching. The leadership of the organisation must be actively engaged in the successful implementation of team coaching. Participant 1 (male, 67 years old) emphasises a 'robust organisational culture that supports team coaching interventions, strong sponsorship and buy-in from senior leadership'. An effective leader collaborates with either his or her counterparts and subordinates. Such a leader creates an opportunity to mitigate the challenges faced when a manager tries to influence areas that are outside of his or her span of control. The coach is the moderator and facilitator aiming at helping the team members' preparation to engage objectively with challenges in the workplace.

The team coach must relate to the organisational culture and have the capacity to understand the diverse nature of the team from a cultural and demographic perspective (participants 3, 4, 5 and 6), 'paying attention to cultural sensitivity' (Participant 5, male, 55 years old). Every level from senior management down to the production line of the workplace should strive to embrace diversity '... you need to get the richness of information from the diverse culture within South Africa' (Participant 3, male, 55 years old). The acknowledgement of diversity acts as a value-adding tool with an improved understanding of all the various units within the workplace: 'An understanding of diversity allows 
one to avoid misguided conclusions' (Participant 4, female, 40 years old). The coaching environment should enable the team to be relaxed and free to provide input without fear of criticism or victimisation. 'New understanding helps them think about how they can relate to one another more effectively, at the same time it breeds tolerance' (Participant 3 , male, 55 years old).

\section{Coaching agreement}

An agreement must be made between the client, who is the sponsor, and the coach. 'Contracting with the sponsor upfront with clear objectives and deliverables ...' (Participant 1, male, 67 years old); it has to be done 'upfront and [with] goal clarity' (Participant 6, female, 58 years old). This has to be in line with the vision of the organisation. The contract should specify the method, goals and expectations of the team coaching intervention. There need to be 'clear objectives, ... [which] get the team to integrate with the individual dynamics as a team' (Participant 4 , female, 40 years old). The agreement must define the roles of all parties as well as the relationship structure. 'Role clarity is important at the contracting stage' (Participant 7, male, 65 years old). The contract must explicitly clarify the agreed outcomes and direction of the process. Coaches must state their flexibility and limitations. This implies that the agreement must not be rigid, but rather should allow for future amendments. The coach needs to be able to 'change direction' if the process does not work well (Participant 2, female, 51 years old). Sufficient resources must be allocated to meet these objectives within team coaching. This may require budget, time allocation and commitment (participants 1, 3 and 7). It may also necessitate the logistics of moving resources to where they are needed to accomplish the set objectives. Organisational dynamics require that the team coaching intervention must fulfil all stakeholders' expectations (Participants 1,2 and 7). A clearly stated contract, guided by the coach who accommodates team dynamics, allows an opportunity to navigate across the stakeholder expectations of the coaching process: 'you need to look at the relationship between the team and its stakeholders, what the various stakeholders are expecting from the team ... and if the team is delivering' (Participant 7, male, 65 years old). The coach must be prepared to manage conflicting ideas from various stakeholders by finding a balance between different expectations.

\section{Team effectiveness}

Team effectiveness is based on the ability to encourage team members to work cohesively towards a common goal within an organisation. Organisations make team effectiveness problematic, as evident from one participant's response: they 'advocate teamwork, however, rewards are based on individual performance' (Participant 3, male, 55 years old). Organisational processes must be coordinated and should combine cognitive, motivational and behavioural resources. Values include encouraging listening and responding constructively to all views expressed, being supportive and acknowledging the interests and achievements of others. The organisational strategy should be clear to the team. If unclear, there will be 'a lack of transparency, lack of integrity and trust, lack of commitment to the goal and the team's performance and poor communication' (Participant 3, male, 55 years old). The outcomes of team coaching implementation have to align with organisational priorities. With effective team coaching implementation, the organisation establishes a synergy across the entire employee engagement system. There has to be an 'agreement with team deliverables' (Participant 2, female, 51 years old). This should take place at the vertical element of senior to lower reporting structures, as well as horizontal reporting levels. Clear team objectives must be set with accurate and timely pre-assessment guidelines. Assessments allow to uncover effective and ineffective team practices. Pre-assessment enables an organisation to determine how to frame the entire engagement and address existing challenges.

\section{Common team goals}

Common team goals allow the 'team to focus and hold each other accountable to the agreed deliverables' (Participant 5, male, 36 years old) and 'pull together towards the same objectives' (Participant 7, male, 65 years old). However, the organisation must first determine what its goals are such that their achievement 'serves the organisations and not individuals' agendas' (Participant 2, female, 51 years old). Confidentiality is vital for the effective implementation of team coaching to safeguard the information shared by the coached individual and to establish a trusting relationship. Successful team results require that all the members of the team are aligned with the objectives. The team then has 'a common team goal which they agree to focus on and hold each other accountable for deliverables' (Participant 5, male, 36 years old). The effect of the sum of multiple agents combined and working in concert will be greater than that of individuals working in isolation. Team coaching adds value through facilitating the collaborative attainment of organisational goals. Parties concerned must invest themselves fully in the activity by giving the necessary attention and effort to complete the task. Individual goals may have to be sacrificed to achieve team goals. Without common goals, a team is just a group of individuals with their own agendas: 'it is designed to achieve its objectives ... example: you can't have 11 players on the soccer field - each person must have their role and complement each other' (Participant 3, male, 55 years old). Consistent feedback will further enhance the team coaching implementation. Feedback can positively contribute to change as stakeholders begin to see the initiative take shape and link the 'why' questions to the results achieved. The coach should provide continuous feedback on team performance, to both the team and the sponsor.

\section{Engagement}

The implementation of new strategies must be clear, as this will bear an impact on the performance of the 
organisational deliverables. Keeping employees engaged should become an organisational priority as employee engagement serves to enhance a positive mindset. 'The aim of team coaching is to foster team engagement which results in team performance' (Participant 1, male, 67 years old). Often organisational leadership formulates new strategies for implementation. Such implementation is optimally introduced through a collaborative approach towards all organisational stakeholders. A collaborative approach is likely to yield higher success when implemented through team coaching. 'Organisations need to implement programmes that improve employee engagement ... team coaching implementation is one of the strategies that can be used to improve employee engagement' (Participant 1, male, 67 years old). A collective approach, where all those affected regularly share their experiences through constant open communication, may promote a healthier environment for team learning.

The continuous monitoring and evaluation of strategies enables all stakeholders to reflect on the effectiveness of team coaching implementation (participants 1, 2, 3, 4 and 7). It allows the organisation to remain objective on executing strategies. A perspective that emerges from the evaluation provides insights into the viewpoints of participants. The organisation is able to measure the successes of the initiative against the established criteria. Regular in-progress evaluations (participants 1, 2, 3, 4 and 7) and post-intervention evaluations of performance continuation should be conducted at intervals ranging from 3 and 6 months to 1 year subsequent to the coaching intervention (participants 2, 3, 4 and 7).

\section{Competencies of the coach}

Qualifications of the team coach also play a vital role in the facilitation of the intervention and competencies of a coach should be well-capacitated in personal development, conflict management, effective communication and team coaching (participants 1, 2, 6 and 7). The coach should be skilled in dealing with team dynamics and in creating a safe space for the team members to express themselves. Participant 7 (male, 65 years old) explains the skills of the coach as a prerequisite in detail:

'Coaching, experience, and sensitivity to understand the difference between individual and team... What works with individual won't work with a team. A good coach should be comfortable with working at all levels ... Coaches must understand the difference between coaching, training, facilitation, mentoring, skills development. All different things ... Coach must be fit for purpose and know when to recommend someone else ... Recognize your own competencies.' (Participant 7, male, 65 years old)

\section{Constraining factors in the implementation of team coaching}

Participants 1 and 7 cited lack of resources, insufficient budget, lack of priority and time allocation, inexperienced team coaches without good facilitation skills or record of accomplishment as contributing factors to poor results in team coaching implementation. Participants 2 and 4 identified lack of transparency as another key constraining factor, along with lack of integrity, trust and commitment to goal attainment for the team. Participant 6 expressed that if the system is not safe for all participants, and there is a lack of leadership, there will be poor trust from the members. The absence of a stakeholder commitment may serve as a major obstacle. This develops when stakeholders are 'not in agreement with the team deliverables and members of the team show resistance to the team coaching intervention ... it will affect results' (Participant 2, female, 51 years old). Competing for personal goals and values may serve as a constraining factor during the implementation phase. The silo effect could also serve as an inhibitor to team coaching implementation (participants 5,6 and 7), where people prefer to work individually.

\section{A conceptual framework for the implementation of team coaching}

The conceptual framework in Figure 1 depicts the key steps involved in the implementation of team coaching. The process is divided into three phases, namely, pre, during and post-implementation, in line with core activities, enablers and constraints.

The framework in Figure 1 highlights the key steps involved in the three phases (pre, during and post) of implementation. The three phases are aligned with core activities, enablers and constraints. The core activities of the pre-implementation stage involve the identification of the need for team coaching and the initiation of a team coaching intervention. During the implementation phase, the core activities are the execution of team coaching, monitoring and assessment of the coaching process, as well as learning, correction and feedback. The post-implementation core activities imply an evaluation of the coaching process, reflection and improvement of the coaching process. Team coaching is implemented in the form of a project with a specific start and end date. Thus, at the end, team coaching would include a project reflection step. This reflection step focuses on the final monitoring and evaluation of team coaching implementation. The outcomes are evaluated against the pre-set objectives. The core activities depict team coaching as a dynamic process, containing a feedback loop, which translates feedback received from assessments and evaluations into learning and self-correction. These learnings are applied to re-assess the core of the team coaching implementation process.

The enablers of the pre-implementation phase involve organisational factors such as the optimisation of cultural diversity and a readiness to participate in the team coaching process. Organisational leadership support refers to sponsorships, the establishment of team coaching outcomes, the allocation of resources to enable a coaching environment and contracting with a coach. Team effectiveness implies the alignment with the strategic goals of the organisation and a 


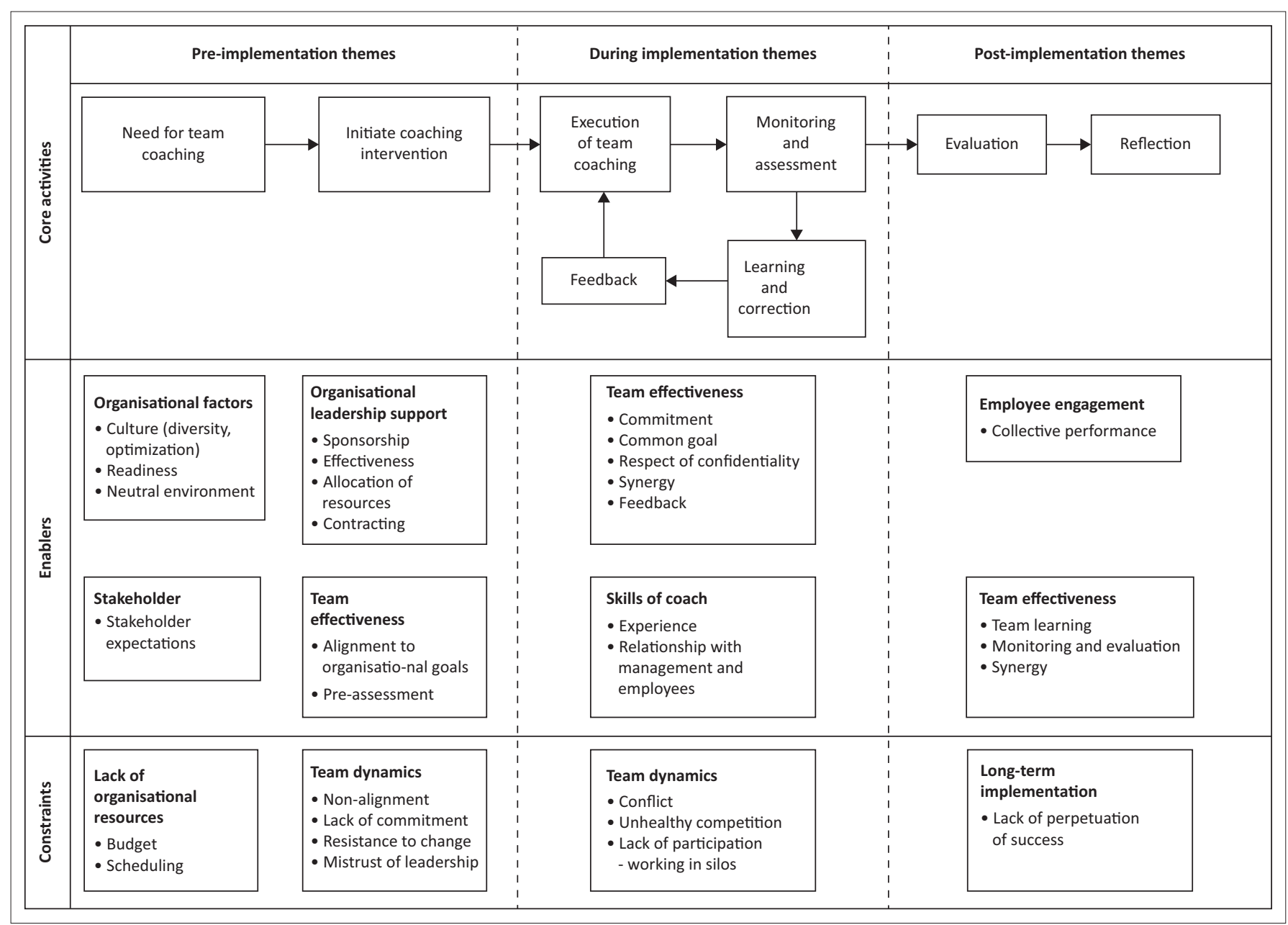

FIGURE 1: Conceptual framework of critical success factors for the implementation of team coaching in associated organisations (current authors)

thorough pre-assessment of what should be accomplished. The pre-implementation phase involves addressing the needs of all stakeholders. Enablers that play a role during implementation include team effectiveness and the skills of the coach. Team effective factors include commitment, identification of common goals, ensuring confidentiality, establishing synergy and providing feedback. The skills of the coach are of utmost importance. The coach needs to be experienced and establish a trusting relationship with both management and employees. Post-implementation enablers refer to continuous monitoring of employee engagement through collective performance and establishment of team effectiveness.

There are certain constraints that may play a role in the pre-, during and post-implementation phases. At preimplementation, there is a danger of a lack of organisational resources because of budget limitation, scheduling challenges and unhealthy team dynamics. These negative team dynamics may lead to non-alignment, a lack of commitment, resistance and mistrust in the coaching process and aims of leadership. During implementation, the process can be adversely affected by counterproductive team dynamics, such as conflict, unhealthy competition and a lack of participation by preferring to work in silos. Postimplementation, the lack of the continuation and monitoring of successful implementation can have a deleterious effect on the ongoing achievement of goals.

\section{Discussion \\ Outline of the findings}

Despite the increasing evidence that teamwork can be a powerful strategy for the realisation of organisational goals, evidence suggests a failure to take advantage of this useful tool (Peters \& Carr, 2013b). In an attempt to establish the factors critical to successful implementation of team coaching, data from the participants were reviewed. The themes are discussed in terms of existent literature and based on the identified phases of team coaching implementation. The identified critical factors that play a role in the successful implementation of team coaching are discussed in terms of existent literature. The first part of the findings focuses on the positive contributors to team coaching implementation, while the latter part of the section focuses on constraining factors.

\section{Pre-implementation phase}

The framework highlights the two key steps during the preimplementation phase: (1) identification of a need for team coaching and (2) initiation of team coaching implementation. 


\section{Organisational context}

Attributes such as culture, strategic objectives, and parameters of team coaching relationship may play a role in the interaction between the coach and the team. In essence, organisational contextualisation refers to strategy and culture, with a focus to improve team engagement and productivity (Bandura \& Lyons, 2017; Morgeson et al., 2010). Strategic contextualisation aligns the objectives, content and outcomes of the team with those of the organisation. This is in line with the argument of Clarke (2010) that team coaching is regarded as a powerful initiation of organisational development. Cultural contextualisation aligns the coachee to the traditions of the organisation. A positive enabling organisational culture may enhance successful implementation of team coaching, where responsibilities and expertise are shared (Mathieu et al., 2000). This finding corresponds to and expands the findings of Nieminen, BiermeierHanson and Denison et al. (2013) which revealed that a coaching culture may play a critical role in building a responsive team of committed leadership.

For the coaching to be beneficial, the teams need to be well structured and supported by leadership (Avolio et al., 2010; Goldman et al., 2013) and may improve both individual and team learning (Matsuo, 2018). Top leader sponsorship will promote a positive experience of team coaching. Leadership should be firmly established and capable of nurturing and channelling the rest of the organisation towards successful team coaching implementation. Team coaching has to be aligned with organisational strategies and should receive leadership support (Mukherjee, 2012). A well-managed diverse workforce may enhance organisational strategic goals. Participants with a wide range of experiences and skill sets result in progressive productive levels and increase the likelihood of breakthrough innovations (Agrawal, 2012). The diversities in skills and experiences allow team members to tackle a project or a task from different points of view, thus creating an opportunity for out-of-the-box thinking.

The findings indicate that leadership trust and competence are key factors for team coach intervention. A leader's trust in team members serves as a crucial element of a highquality leader-team relationship. Both trust in the coaching relationship (Clutterbuck, 2013) and trust in leadership must be respected. The current study emphasised the importance of contracting at the onset of the intervention, clearly defining the obligations and expectations of all stakeholders. This is in line with the arguments of Mukherjee (2012) that initiatives need to be aligned with organisational strategies. The participants highlighted the need to consider stakeholders' expectations prior to team coaching implementation, as this will enable the alignment of team coaching interventions with organisational goals. Ashley-Timms (2012) emphasises that all stakeholders' anticipations need to be acknowledged and aligned with organisational needs, especially when the organisation is the ultimate sponsor of such intervention.

The findings emphasise the importance of organisational readiness and pre-assessment as a key to the team coaching implementation strategy. This may provide guidance to best proceed and indicate expectations. Rousseau et al. (2013) confirm that analyses of pre-coaching questionnaires will assist in measuring the level of interest and key areas to focus on. Such information could contribute to the application of the most appropriate approach according to the dynamics and structure of the team. It provides a platform for the transformation of skills and development of knowledge behaviour (Sessa et al., 2011; Vesso \& Alas, 2016).

\section{During implementation phase}

During the implementation phase, key activities are the execution of team coaching, monitoring, assessment and evaluation. The framework reflects the team coaching process as a dynamic process, containing a feedback loop that translates feedback received from assessments and evaluations into learning and self-correction. Information gained through feedback should be applied to rectify the core team coaching implementation process where necessary. The themes associated with the implementation phase are subsequently discussed.

\section{Team effectiveness}

Any meaningful team coaching initiative should be linked to some organisational strategic objectives rather than conducted for its own sake. Team effectiveness is about maximising the team's contribution to the attainment of organisational strategic objectives (Rousseau et al., 2013). Regardless of the level of the team coach engagement, the sponsor and the team coach must formulate a plan that is cognisant of and integrates organisational strategy, vision and values (Clutterbuck, 2013). The participants' consent and commitment are viewed as critical to team coaching implementation. The coachees' willingness and buy-in from the team members along with the team coaching intervention allow for improved success. It is fundamental that team coaching takes place in a conducive environment (Ingleton, 2013). The participants posited that an effective team coaching process requires confidentiality and trust. At the outset of the intervention, the coach and the team must establish a common understanding of trust, confidentiality, empathy and deep listening (Clutterbuck, 2013). Self-reflection and sensitisation to self-awareness may play an important role in this regard (Peuker \& Kiss, 2018). Team coaching is viewed as a strategic space for the enhancement of collective member capabilities and improvement of participation levels (Solansky \& McIver, 2017). Collaborative teams share information and promote knowledge empowerment that translates to innovative teams (Gallant \& Gilham, 2014), with subsequent perceived influence on organisational culture.

For effective team coaching, the participants emphasised that coaches should be competent, accomplished and skilled. A team coach should seek to simplify organisational strategies and objectives (Mukherjee, 2012), vision, team dynamics, team incentives, responsibilities, timelines and measures. 
The study conducted by Vandaveer, Lowman, Pearlman and Brannick (2016) reveals three top critical success factors that impacted the implementation of team coaching: (1) coach quality, (2) coachee readiness and (3) strength of the coach-team relationship. Establishing the coach-coachee relationship is the primary step in any coaching engagement. This provides a platform for the rules of engagement and accountability (Kahn, 2011) and ultimately influences the strength of their relationship. A fundamental factor influencing the ability of a coach and coachee to work well together is the establishment of a list of criteria compiled by both parties (Clutterbuck, 2013). This is in line with Kahn's (2011) observation that the role and accountability of the parties should be established and contracted from the start. The majority of the participants cited the importance of having periodic and consistent feedback sessions between team members and to leadership. These feedback sessions can comprise regular checking in sessions. The sponsor should receive feedback during and after team implementation. The type of feedback must be agreed in advance, during the contracting, pre-implementation phase.

\section{Post-implementation phase}

In a workplace setting, team coaching is implemented in the form of a project with a defined start and end date. Thus, at the end, team coaching should include a project reflection step where the continuation of intervention outcomes is closely monitored (Anderson, 2011; Avolio et al., 2010; Osatuke et al., 2016). Critical reflection focuses on the final monitoring and evaluation of team coaching implementation against the objectives, as well as any correction that may be required in future team coaching interventions. The postimplementation phase would include a project reflection step. This reflection step focuses on the final monitoring and evaluation of team coaching implementation. Set objectives may allow an organisation to obtain in-time outcomes, as they give the organisation an opportunity to critically assess progress, and an opportunity to intervene if necessary.

\section{Employee engagement}

Participants identified employee engagement as a critical factor for successful team coaching implementation, which resonates with Nelson and Hogan's (2009) assertion that organisations should prioritise engagement with employees. The participants highlighted that employee engagement promotes a progressive relationship as managers begin to trust their employees' input. According to the participants, these improved relations contribute to employee performance and turnaround time, further enhancing productivity. The coach-client relationship further influences the way in which a coach challenges and supports the team so that new ways of thinking are developed in order to achieve teampersonalised and organisational goals. Through an input of learning and transformation, an output of the relationship and task orientation is achieved that influences levels of engagement (Vesso \& Alas, 2016). Participants identified team learning as a pivotal objective to organisational values. Central to team coaching is the cultivation of learning among team members. Teams provide the platform for knowledge sharing and exchange for which organisational learning becomes the product. Team learning is effective when there is a permanent change in skills, knowledge and behaviour of the team (Sessa et al., 2011).

\section{Monitoring and evaluation}

Participants highlighted that a variety of techniques can be applied to sustain and embed coaching in organisations, such as evaluation of the post-coaching implementation outcomes vis-à-vis or compared to the initial team coaching expectations. Surveys of the team and all stakeholders after the intervention are crucial for the evaluation of the team coaching exercise. As affirmed by Anderson (2011) and Avolio et al. (2010), the business impact, emergence of team relations and collaborations are aspects that must be measured after team coaching. This evaluation should perhaps take place a couple of months after the activity to allow reasonable time for gathering evidence to provide an authentic assessment.

\section{Constraining factors}

The study identified some constraining factors, with insufficient budget cited by the majority of participants as one of the critical factors in team coaching failure. This is similar to Chapman's (2010) argument that resource limitations could hinder the success of team coaching. The participants highlighted the absence or lack of commitment to overall team performance. This ties in with the reasoning of Guidroz, Luce and Denison (2010) that the absence of collaboration and 'working in silos' hamper the success of a team coaching intervention.

\section{Practical implications}

The literature demonstrates that dyadic coaching remains dominant. The findings of the current study provide a platform that enhances our understanding of the complexities of team coaching within organisations. High performance is at the centre of successful team coaching, which promotes meaningful collaboration. Team coaching signifies a method of leadership development that moves beyond the individual to development at a team level. Team coaching could serve as a critical platform for team work, collaboration and leadership development.

\section{Limitations and recommendations}

The study only concerned itself with teams within the workplace. The study did not include other team settings. Findings reflect the views of team coaches and not the coachees. Sample bias may have played a limiting role, as purposive and snowballing techniques were employed. Future research could benefit by including all the 
stakeholders, coaches, coachees, leadership and executive management to provide multiple perspectives on team coaching. Future quantitative investigations could add insights into the effectiveness of team coaching. The advantages and disadvantages of dyadic coaching compared to team coaching need further investigation.

\section{Conclusion}

The current study contributes to the body of evidence on team coaching in the workplace. A number of critical success factors were identified, which contribute to the foundation of a conceptual team coaching framework. This framework represents team coaching as an interactive process with feedback loops that provide continuous review and improvement opportunities for the pre-implementation, implementation and post-implementation stages.

\section{Acknowledgements}

The authors would like to thank the participants for volunteering to take part in the study, and for sharing their experience and expertise.

\section{Competing interests}

The authors declare that they have no financial or personal relationships that may have inappropriately influenced them in writing this article.

\section{Authors' contributions}

B.M.M. is the master's student and this work is from her dissertation. R.v.W. was the supervisor of this research and responsible for guidance and literature, and was involved in analysis. A.O. was the co-supervisor of the study and responsible for guidance and literature, and was involved in analysis.

\section{References}

Agrawal, V. (2012). Managing the diversified team: Challenges and strategies for improving performance. Team Performance Management: An International Journal, 18(7/8), 384-400. https://doi.org/10.1108/13527591211281129

Anderson, M. (2011). Evaluating the ROI of coaching: Telling a story, not just producing a number. In $\mathrm{G}$.

Ashley-Timms, L. (2012). Return on investment guaranteed: Effecting transformation and sustaining change with coaching. Industrial \& Commercial Training, 44(3), 159-163. https://doi.org/10.1108/00197851211216763

Avolio, B. J., Avey, J. B., \& Quisenberry, D. (2010). Estimating return on leadership development investment. Leadership Quarterly, 21(4), 633-644. https://doi.org/ 10.1016/j.leaqua.2010.06.006

Bandura, R. P., \& Lyons, P. R. (2017). Using a skill-building tool to enhance employee engagement. Human Resource Management International Digest, 25(6), 1-5. https://doi.org/10.1108/HRMID-04-2017-0064

Baxter, P., \& Jack, S. (2008). Qualitative case study methodology: Study design and implementation for novice researchers. The Qualitative Report Volume, 13(4), 544-559. https://doi.org/10.2174/1874434600802010058

Blumberg, B., Cooper, D. R., \& Schindler, P. S. (2011). Business research methods (3rd edn.). London: McGraw-Hill Higher Education.

Bond, A., \& Naughton, N. (2011). The role of coaching in managing leadership transitions. International Coaching Psychology Review, 6(2), 165-179.

Britton, J. J. (2015). Expanding the coaching conversation: Group and team coaching. Industrial \& Commercial Training, 47(3), 116-120. https://doi.org/10.1108/ICT10-2014-0070
Chapman, L. (2010). Integrated experiential coaching: Becoming an executive coach. London: Karnac Books.

Clarke, N. (2010). Emotional intelligence and learning in teams. Journal of Workplace Learning, 22(3), 125-145. https://doi.org/10.1108/13665621011028594

Clutterbuck, D. (2013). Time to focus coaching on the team. Industrial and Commercia Training, 45(1), 18-22. https://doi.org/10.1108/00197851311296665

Collis, J., \& Hussey, R. (2009). Business research: A pratical guide for undergraduates \& postgraduate students (3rd edn.). New York, NY: Palgrave MacMillan.

Gallant, A., \& Gilham, V. (2014). Differentiated coaching: Developmental needs of coachees. International Journal of Mentoring and Coaching in Education, 3(3), 237-254. https://doi.org/10.1108/IJMCE-12-2013-0059

Goldman, E., Wesner, M., \& Karnchanomai, O. (2013). Reciprocal peer coaching: A critical contributor to implementing individual leadership plans. Human Resource Development Quarterly, 24(1), 63-87. https://doi.org/10.1002/hrdq 21153

Grant, A. M. (2012a). An integrated model of goal-focused coaching: An evidencebased framework for teaching and practice. International Coaching Psychology Review, 7(2), 146-165. https://doi.org/10.1080/17521880903102308

Grant, A. M. (2012b). ROI is a poor measure of coaching success: Towards a more holistic approach using a well-being and engagement framework. Coaching: An International Journal of Theory, Research and Practice, 5(2), 74-85. https://doi.or $\mathrm{g} / 10.1080 / 17521882.2012 .672438$

Greeff, M. (2005). Information collection: Interviewing. In A. S. De Vos, C. B. Fouché, \& C. S. L. Delport (Eds.), Research at grass roots: For the social sciences and human service professions (3rd edn., pp. 286-313). Pretoria: Van Schaik.

Guest, S., \& Mitchell, M. (2007). Collecting qualitative data: A field manual for applied research. London: Sage.

Guidroz, A. M., Luce, K. W., \& Denison, D. R. (2010). Integrated change: Creating synergy between leader and organizational development. Industrial and Commercial Training, 42(3), 151-155. https://doi.org/10.1108/00197851011038141

Hackman, J., \& Wageman, R. (2005). A theory of team coaching. Academy of Management Review, 30(2), 269-287. https://doi.org/10.5465/amr.2005. 16387885

Hagen, M., \& Aguilar, M. G. (2012). The impact of managerial coaching on learning outcomes within the team context: An analysis. Human Resource Development Quarterly, 23(3), 363-388. https://doi.org/10.1002/hrdq.21140

Hamlin, R. G., Ellinger, A. D., \& Beattie, R. S. (2008). The emergent 'coaching industry': A wake-up call for HRD professionals. Human Resource Development International, 11(3), 287-305. https://doi.org/10.1080/13678860802102534

Hawkins, P. (2014). Leadership team coaching: Developing collective transformational leadership. Philadelphia, PA: Kogan Page.

Hernez-Broome, B., \& Boyce, L. A. (Eds.), Advancing executive coaching: Setting the course for successful leadership coaching (pp. 351-368). San Francisco, CA: Jossey-Bass.

Ingleton, C. (2013). The miracle of coaching. Industrial and Commercial Training, 45(5), 289-292. https://doi.org/10.1108/ICT-03-2013-0018

Joo, B. K. (2005). Executive coaching: A conceptual framework from an integrative review of practice and research. Human Resource Development Review, 4(4), 462-488. https://doi.org/10.1177/1534484305280866

Kahn, M. S. (2011). Coaching on the axis: An integrative and systemic approach to business coaching. International Coaching Psychology Review, 6(2), 337-347.

Kampa-Kokesch, S., \& Anderson, M. (2001). Executive coaching a comprehensive review of the literature. Consulting Psychology Journal, 53(4), 205-228. https:// doi.org/10.1037//1061-4087.53.4.205

Klein, C. (2012). Research will evolve, but we must do a better job of translating what we already know. Industrial and Organizational Psychology, 5(1), 52-55. https:// doi.org/10.1111/j.1754-9434.2011.01405.x

Kozlowski, S. W. J., \& Ilgen, D. R. (2006). Enhancing the effectiveness of work groups and teams. Psychological Science in the Public Interest, 7(3), 77-124. https://doi. org/10.1111/j.1529-1006.2006.00030.x

Leedy, P. D., \& Ormord, J. E. (2001). Practical research: Planning and design. Ohio, NJ: Merill Prentice Hall.

Martiz, M. (2012). High performance team coaching: A positive deviant exploration. M.Com. [Unpublished Thesis]. University of Johannesburg.

Mathieu, J. E., Heffner, T. S., Goodwin, G. F., Salas, E., \& Cannon-Bowers, J. A. (2000). The influence of shared mental models on team process and performance. The Journal of Applied Psychology, 85(2), 273-283. https://doi.org/10.1037/00219010.85.2.273

Matsuo, M. (2018). How does managerial coaching affect individual learning? The mediating roles of team and individual reflexivity. Personnel Review, 47(1), 118-132. https://doi.org/10.1108/PR-06-2016-0132

Mayan, M. J. (2009). Essentials of qualitative inquiry. Walnut Creek, CA: Left Coast Press.

McDermott, M., Levenson, A., \& Newton, S. (2007). What coaching can and cannot do for you organisation. Human Resource Planning, 30(2), 30-37.

Miles, M. B., Huberman, M. A., \& Saldana, J. (2013). Qualitative data analysis. Los Angeles, CA: Sage Publications.

Morgeson, F. P., DeRue, D. S., \& Karam, E. P. (2010). Leadership in teams: A functional approach to understanding leadership structures and processes. Journal of Management, 36(1), 5-39. https://doi.org/10.1177/0149206309347376 
Mukherjee, S. (2012). Does coaching transform coaches? A Case study of internal coaching. International Journal of Evidence Based Coaching and Mentoring, 10(2), $76-87$.

Nelson, E., \& Hogan, R. (2009). Coaching on the dark side. International Coaching Psychology Review, 4, 9-21.

Newman, L. (2012). Basics of social research: Qualitative \& quantitative approach Upper Saddle River, NJ: Pearson.

Nieminen, L., Biermeier-Hanson, B., \& Denison, D. (2013). Aligning leadership and organizational culture: The leader-culture fit framework for coaching organizationa leaders. Consulting Psychology Journal: Practice and Research, 65(3), 177-198. https://doi.org/10.1037/a0034385

Odendaal, A. (2016). Leadership coaching. In T. H. Veldsman, A. Johnson, \& W. Crous (Eds.), Leadership: Perspectives from the front line (pp. 631-649). Johanesburg. Knowledge Resources.

Osatuke, K., Yanovsky, B., \& Ramsel, D. (2016). Executive coaching: New framework for evaluation. Consulting Psychology Journal: Practice and Research, 69(3), 172-186.

Patton, M. Q. (1990). Qualitative evaluation and research methods. Newburry Park, CA: Sage.

Peters, J., \& Carr, C. (2013a). High performance team coaching. Calgary: InnerActive Leadership Associates Inc.

Peters, J., \& Carr, C. (2013b). Team effectiveness and team coaching literature review. Coaching: An International Journal of Theory, Research and Practice, 6(2), 116-136. https://doi.org/10.1080/17521882.2013.798669

Peuker, G., \& Kiss, O. (2018, June). Development of executives in Agile organisation Paper presented at the 5th International Coaching Conference (pp. 12-13) University of Applied Sciences and Arts Northwestern Switzerland, Otten Switzerland.

Pope, C., Ziebland, S., \& Mays, N. (2000). Analysing qualitative data. British Medica Journal, 320(8), 114-116. https://doi.org/10.1192/bjp.109.458.163

Reich, Y., Ullmann, G., Van der Loos, M., \& Leifer, L. (2009). Coaching product development teams: A conceptual foundation for empirical studies. Research in Engineering Design, 19, 205-222. https://doi.org/10.1007/s00163-008-0046-1

Reid, M. A. (2012). The impact of group coaching on leadership effectiveness in South African woman managers. Johannesburg: University of the Witwatersrand.
Rekalde, I., Landeta, J., \& Albizu, E. (2015). Determining factors in the effectiveness of executive coaching as a management development tool. Management Decision, 53(8), 1677-1697. https://doi.org/10.1108/MD-12-2014-0666

Rousseau, V., Aubé, C., \& Tremblay, S. (2013). Team coaching and innovation in work teams: An examination of the motivational and behavioral intervening mechanisms. Leadership \& Organization Development Journal, 34(4), 344-364. https://doi.org/ 10.1108/LODJ-08-2011-0073

Sessa, V. I., London, M., Pingor, C., Gullu, B., \& Patel, J. (2011). Adaptive, generative, and transformative learning in project teams. Team Performance Management, 17(3/4), 146-167. https://doi.org/10.1108/13527591111143691

Scotland, J. (2012). Exploring the philosophical underpinnings of research: Relating ontology and epistemology to the methodology and methods of the scientific, interpretive and critical research paradigms. English Language Teaching, 5(9), 9-16. https://doi.org/10.5539/elt.v5n9p9

Solansky, S., \& Mclver, D. (2017). Team characteristics and leadership training participation. Team Performance Management, 24(3/4), 135-149. https://doi.org/ https://doi.org/10.1108/TPM-12-2016-0055

Standards Australia. (2010). Standards Australia Guidelines for Coaching in Organisations. Sydney: Standards Australia.

Thornton, C. (2010). Group and team coaching: The essential guide by Christine Thornton. New York: Routledge.

Vandaveer, V. V., Lowman, R. L., Pearlman, K., \& Brannick, J. P. (2016). A practice analysis of coaching psychology: Towards foundational competency model. Consulting Psychology Journal, 68(2), 118-142.

Vesso, S., \& Alas, R. (2016). Characteristics of a coaching culture in leadership style the leader's impact on culture. Problems and Perspectives in Management, 14(2), 306-318. https://doi.org/10.21511/ppm.14(2-2).2016.06

Wageman, R., Fisher, C. M., \& Hackman, J. R. (2009). Leading teams when the time is tight: Finding the best moment to act. Organizational Dynamics, 38(3), 192-203. https://doi.org/10.1016/j.orgdyn.2009.04.004

Welman, C., Kruger, F., \& Mitchell, B. (2005). Research methodology (3rd edn.). Cape Town: Oxford University Press.

Yates, K. (2015). Managing, tracking and evaluating coaching part 2: Where could you be Industrial and Commercial Training, 47(2), 95-98. https://doi.org/10.1108/ ICT-08-2014-0058 